\title{
Endovascular and Surgical Treatment of Acute Deep Vein Thrombosis
}

\section{Akut Derin Ven Trombozunda Endovasküler ve Cerrahi Tedavi}

\author{
(D) Tünay Kurtoğlu, (D) Selim Durmaz, (D) Berent Dişçigil \\ Aydın Adnan Menderes University Faculty of Medicine, Department of Cardiovascular Surgery, Aydın, Turkey
}

\begin{abstract}
Keywords
Deep vein thrombosis, thrombolysis, percutaneous, thrombectomy
\end{abstract}

\author{
Anahtar Kelimeler \\ Derin ven trombozu, trombolizis, perkütan, \\ trombektomi
}

Received/Geliş Tarihi : 01.07.2015

Accepted/Kabul Tarihi : 11.08.2015

doi:10.4274/meandros.galenos.2015.2366

Address for Correspondence/Yazışma Adresi: Tünay Kurtoğlu MD,

Aydın Adnan Menderes University Faculty of Medicine, Department of Cardiovascular Surgery, Aydın, Turkey

E-mail :drtunaykurtoglu@gmail.com

ORCID ID: orcid.org/0000-0003-2168-2891

(C) Meandros Medical and Dental Journal, Published by Galenos Publishing House.

This is article distributed under the terms of the Creative Commons Attribution NonCommercial 4.0

International Licence (CC BY-NC 4.0).

\begin{abstract}
Acute deep vein thrombosis (DVT) has a high mortality and a significant morbidity risk. The most dreadful early complications of DVT are pulmonary embolism (PE) and phlegmasia cerulea dolens, which is a consequence of circulatory impairment due to venous obstruction. Another important complication is Post-thrombotic syndrome (PTS), which may significantly reduce the quality of life in the long term. Anticoagulation is the cornerstone of treatment in DVT and has been proven to reduce the risk of fatal PE by avoiding thrombus propagation. However, anticoagulant therapy may be ineffective in preventing venous gangrene and PTS caused by chronic venous obstruction and venous valvular incompetence. Endovascular treatment options, such as catheter-directed thrombolysis, percutaneous mechanical thrombectomy, venous angioplasty/stenting and surgical venous thrombectomy, can help remove acute thrombus and restore venous patency. These methods can be performed as an adjunct to anticoagulant therapy and are becoming the treatment of choice in extremity-threatening venous ischaemia, as well as in iliofemoral venous thrombosis, and in vena cava thrombosis where the risk of PE is high. In this study, we aim to review the thrombus removal methods used in the treatment of acute DVT.
\end{abstract}

Öz

Akut derin ven trombozu (DVT) yüksek mortalite ve belirgin morbidite riski taşımaktadır. Erken dönemde pulmoner embolizm (PE) ve venöz tıkanıklığa bağlı dolaşım bozukluğunun sonucu olan phlegmasia cerulea dolens en çok korkulan komplikasyonlardır. Ayrıca uzun dönemde Post-trombotik sendrom (PTS) yaşam kalitesinde ciddi azalmaya neden olabilmektedir. Antikoagülasyon akut DVT'de tedavinin temelini oluşturmaktadır ve trombozun ilerlemesini engelleyerek ölümcül PE riskini azalttığı kanıtlanmıştır. Ancak antikoagülan tedavi venöz gangreni, venöz kapakçık yetmezliğini ve kronik venöz tıkanıklığın yol açtığı PTS'yi engellemekte yetersiz kalabilmektedir. Kateter aracılı trombolizis, perkütan mekanik trombektomi, venöz anjiyoplasti/stentleme gibi endovasküler tedavi yaklaşımları ve cerrahi venöz trombektomi, akut trombüs yükünün temizlemesini ve venöz açıklığı sağlayabilmektedir. Antikoagülasyon ile birlikte uygulanan bu yöntemler, ekstremiteyi tehdit eden venöz iskemide, iliofemoral trombozda ve PE riskinin yüksek olduğu vena kava trombozunda öncelikli tedavi seçeneği haline gelmeye başlamıştır. Bu derlemede akut DVT tedavisinde kullanılan trombüs temizleme yaklaşımlarının güncel literatür bilgileri eşliğinde gözden geçirilmesi amaçlanmıştır. 


\section{Introduction}

Venous thromboembolism (VTE) is defined as the formation of an embolus somewhere within the venous system and the partial or complete obstruction of the venous blood circulation. The incidence of VTE was reported to be 117 out of 100.000 in general population and the risk is increased in elderly (1). VTE typically occurs in the lower extremity veins such as the femoral and the popliteal veins or the deep pelvic veins, and this pathology is named as deep vein thrombosis (DVT).

The most important complication of acute DVT is a pulmonary embolism (PE), which carries a high mortality risk. It has been reported that the annual incidence of acute DVT episode is one million and 100.000 patients die due to PE each year in the USA (2). However, the complications of lower extremity acute DVT are not limited to PE. Venous thrombosis can cause damage to the vessel wall and venous valves or may cause permanent venous obstruction (3). These chronic changes may result in venous valve incompetence, venous reflux, and venous hypertension. The ongoing pathological process may eventually lead to edema, pain, varicosities, venous claudication, and ulceration within one to two years following the acute DVT episode. This clinical presentation is known as Postthrombotic syndrome (PTS) which is a common complication of DVT that adversely affects the patient's daily life meanwhile leading to significant increases in healthcare costs $(4,5)$.

Current treatment guidelines recommend parenteral anticoagulation as the initial therapy and to continue with vitamin $\mathrm{K}$ antagonists for at least three months in patients with DVT or PE $(6,7)$. Anticoagulant therapy prevents the propagation of thrombus and reduces the risk of PE significantly (3). However, in more than $50 \%$ of patients with acute DVT episode residual venous thrombus was found following an appropriate anticoagulant therapy $(8,9)$. The residual thrombus may act as a focus that can lead to formation of new thrombus and can be the cause of thrombus expansion following the acute episode. The presence of residual thrombus after anticoagulant therapy increases the risk of DVT recurrence $(10,11)$. Residual thrombus is also found to be related to PTS and indicates 1.5 to 1.6 -fold increased risk $(12,13)$.
As a result, almost half of the DVT patients managed with anticoagulant therapy alone suffer PTS after one year of follow-up and severe complications including venous ulceration may occur in $5-10 \%$ of these patients (14). The only method that has been recommended to avoid the development of PTS is using elastic compression socks; however, this method enables prevention in only $50 \%$ of the cases $(15,16)$.

In recent years, employment of invasive treatment approaches providing the active removal of thrombus in order to relieve acute symptoms, prevent venous reflux and obstruction, and reduce the risk of PTS development has been suggested as an alternative to conventional medical treatment in acute DVT (Table 1). In this review, we aimed to summarize the surgical and percutaneous interventional methods for acute DVT treatment.

The Localization of Acute Thrombus and Its Clinical Effects

Acute lower extremity DVT has been classified anatomically as proximal (popliteal vein and veins located proximal to popliteal vein) or distal (calf veins and distal veins) thrombosis. Proximal DVT includes thrombosis in femoropopliteal and the iliofemoral segments. Although this classical classification is clinically appropriate, it is inadequate regarding the prediction of long-term morbidities and the course of the disease.

The deep femoral vein which drains to the iliac vein via the main femoral vein acts as an important collateral vessel in the presence of a limitation in the main venous flow pathway (17). Therefore, in case of an isolated infrainguinal venous obstruction lower limb venous return can still carry on. However, venous drainage of the lower extremity is severely impaired

\begin{tabular}{|c|c|}
\hline \multirow{3}{*}{ Pharmacological thrombolysis } & Systemic \\
\hline & Flow-directed \\
\hline & Catheter-directed \\
\hline \multirow{4}{*}{$\begin{array}{l}\text { Percutaneous mechanical } \\
\text { thrombectomy }\end{array}$} & Rheolytic \\
\hline & Rotational \\
\hline & Ultrasound-facilitated \\
\hline & Aspiration \\
\hline \multicolumn{2}{|c|}{ Pharmacomechanical thrombolysis } \\
\hline \multicolumn{2}{|l|}{ Surgical venous thrombectomy } \\
\hline
\end{tabular}


when the thrombosis involves the common iliac or the femoral veins. In $25 \%$ of symptomatic lower extremity venous thrombosis, either or both the iliac and femoral veins are involved and this condition is called iliofemoral DVT (18).

Illiofemoral DVT (IFDVT) may cause drastic symptoms with a significant thrombus burden. Phlegmasia cerulea dolens (PCD) is a clinical picture characterized by massive edema, cyanosis, and pain due to diffuse venous thrombosis. The underlying mechanism of this rare clinical condition is the collapse of small arteries due to increased compartment pressure as a result of severe venous hypertension and tissue edema $(19,20)$. It indicates an intensive circulatory disorder that can lead to loss of extremity and therefore its treatment in the early period has an utmost importance.

Recurrence of thrombosis following an acute DVT episode is the major risk factor for PTS (21). It was reported that the risk of venous thrombosis recurrence in patients who had been treated with conventional anticoagulant treatment is 2 to 4-fold higher in iliofemoral thrombosis compared to femoropopliteal involvement (22). The rates of ambulatory venous hypertension, chronic venous hypertension, venous ulceration and venous claudication in IFDVT patients following five years of anticoagulant therapy were reported to be $95 \%, 90 \%, 15 \%$ and $15 \%$, respectively, (23).

Patients with thrombosis of common femoral vein or iliac vein have a considerably higher risk of PTS when compared to patients with distal venous thrombosis (24). Therefore, it was asserted that a treatment modality enabling thrombus removal as an adjunct to anticoagulant therapy could be beneficial in acute IFDVT to reduce morbidity.

\section{Early Thrombus Removal in Acute Deep Venous Thrombosis}

The treatment methods which aim at thrombus removal in acute DVT can help to maintain venous blood circulation, to reduce inflammatory response, and to preserve the integrity of venous walls and venous valvular functions (25). These treatments help to achieve a quick relief of symptoms such as pain and edema in the affected extremity while decreasing the risk of PE and avoiding long-term postthrombotic morbidity (18). Such a therapeutic approach may be preferred in patients with diffuse thrombus burden and in consequence a higher risk of $\mathrm{PE}$. The conventional treatment has a limited success rate in phlegmasia cerulea dolens ( $P C D)$, so the thrombus should be removed and venous circulation should be immediately restored to prevent the development of venous gangrene (Table 2) (26).

Early thrombus removal approach should be performed in young or active patients in whom the symptoms have a short course. The patients with short life expectancy, who are bedridden, or who have a chronic or critical disease are generally not regarded as candidates for invasive thrombus removal techniques (27). Comorbidities that can increase the risk of complications including active bleeding, intracranial pathologies, history of recent trauma or surgery, severe liver dysfunction, gastrointestinal bleeding, uncontrolled hypertension, pulmonary hypertension, cardiopulmonary disorders, kidney failure and acute infection should be evaluated before using such methods (Figure 1).

Society for Vascular Surgery in collaboration with American Venous forum have published "Early Thrombus Removal Strategies for Acute Deep Venous Thrombosis" guideline in 2012 and recommended the use of thrombus removal methods in selected patients. It was emphasized that ambulatory patients who have undergone their first IFDVT episode, whose symptoms have lasted less than 14 days, who have a low bleeding risk, optimal functional capacity, and a considerable life expectancy are good candidates for thrombus removal. It was also recommended that strategies regarding early thrombosis removal might be the treatment of choice in the presence of extremity-threatening ischemia due to IFDVT and conventional anticoagulant treatment should be chosen in cases with femoropopliteal DVT (28).

\section{Systemic Thrombolysis}

Thrombolytic agents disintegrate the thrombus through activation of plasminogen. Plasmin, which is formed by activation of plasminogen, breaks down

Table 2. The potential benefits of thrombus removal in acute deep vein thrombosis

Achieving venous patency and treating acute symptoms

Reducing the risk of pulmonary embolism

Eliminating the risks of venous ischemia and gangrene development

Preventing the post-thrombotic syndrome 
the bonds between fibrin molecules constituting the thrombus. Thrombolytic agents, which help to accelerate thrombus resolution, can be used systemically via peripheral venous infusion in acute DVT to restore venous patency. The period in which thrombolytic treatment is most effective is the acute phase ( $<3$ days), and the efficacy of the treatment decreases within time, especially when the duration of thrombosis exceeds four weeks (27).

The studies comparing the anticoagulation and the systemic thrombolysis have revealed that the thrombolytic therapy is better in restoring venous patency and improvement of venous hemodynamics in the early period. Systemic thrombolysis leads to a $50 \%$ reduction of PTS risk when compared to conventional treatment in middle course $(28,3)$. The rate of venous valvular incompetence was $9 \%$ following successful thrombolysis whereas this rate was $77 \%$ if the thrombolysis was not achieved (29).

Laboratory and clinical studies have revealed that systemic administration of thrombolytic agents cannot achieve sufficient effectiveness in DVT therapy. The lack of effectiveness is probably due to the inactivation of thrombolytic agents by potential circulating inhibitors and the incomplete diffusion of the thrombolytic agent into the matrix structure of the venous thrombus. The success rate of thrombolysis in partially obstructed venous segments was reported to be $50 \%$ but this rate decreases to $10 \%$ when the vessel is completely obstructed (30). Indeed, systemic thrombolytic treatment causes a significant increase in risk of major hemorrhagic complications when compared to anticoagulant therapy used alone $(3,31)$.

Thrombolytic treatment is contraindicated in numerous conditions that can increase the rate of hemorrhagic complications. In general, one out of five patients diagnosed as DVT is a suitable candidate for thrombolytic treatment (32). Active internal hemorrhage, hemorrhagic diathesis such as disseminated intravascular coagulation, cerebrovascular event, recent neurosurgical intervention (intracranial or spinal), cranial or other major trauma within last 3 months, suspect of aortic dissection and general contraindications for anticoagulant use are absolute contraindications for thrombolytic therapy $(26,7)$. Relative contraindications for thrombolytic treatment includes history of major surgery, recent child delivery, or cardiopulmonary resuscitation within last ten days, intracranial tumor or other cerebrovascular disorders, pregnancy, gastrointestinal hemorrhage within last 3 months, uncontrolled severe hypertension (systolic blood pressure $>180 \mathrm{~mm} / \mathrm{Hg}$, diastolic blood pressure $>90 \mathrm{~mm} / \mathrm{Hg}$ ), thrombolytic or radiocontrast agent allergy, right to left intracardiac or pulmonary shunt, thrombus located in the left heart, bacterial endocarditis, and renal failure (serum creatinine level $>2 \mathrm{mg} / \mathrm{dL})(26,7,33)$.

Systemic thrombolytic treatment has not reached a widespread use due to high hemorrhage risk and low probability of achieving complete thrombus resolution. However, the better results of systemic thrombolysis regarding complete thrombus resolution and reduction of PTS risk when compared to conventional anticoagulant therapy has provided a basis for development of thrombolytic treatment methods.

\section{Catheter-directed Thrombolysis}

Methods that allow intensive delivery of the thrombolytic agent to the close vicinity of the thrombus can be divided into two main groups as catheter-directed thrombolysis (CDT) and flow-directed thrombolysis. Catheter-directed thrombolytic treatment enables the thrombolytic agent to be administered within the thrombus by using interventional techniques under fluoroscopy guidance. The thrombus-focused administration of the thrombolytic agent allows using lesser doses and faster thrombus removal with reduced risk of systemic side effects. In flow-directed thrombolytic treatment the thrombolytic agent is delivered into the deep venous system via an ipsilateral dorsal foot vein. Although thrombolysis can be achieved in crural veins with flow-directed thrombolytic treatment, this method is of limited use since it requires a larger thrombolytic agent dose compared to CDT.

Catheter-directed thrombolytic treatment has been recommended as an adjunctive therapy to conventional anticoagulation in patients with severe proximal deep venous thrombosis in American Society of Interventional Radiology (2006) and American Heart Association (2011) guidelines (26,7). American College of Chest Physicians also recommended anticoagulant therapy as the primary treatment choice in acute proximal DVT in "antithrombotic treatment and thrombosis prevention in VTE 
disorder" guideline (2012); however it was suggested that catheter-directed thrombolytic treatment might be preferred in IFDVT patients in whom the duration of symptoms is less than 14 days, with optimal functional capacity, more than 1-year life expectation, and low hemorrhage risk (6).

The venous access in CDT is carried out by percutaneous intervention. The entrance into the vein is usually performed under ultrasonographic guidance and by using small caliber needles to avoid damage to vessel wall and neighbouring arteries (26). The procedure should be performed under fluoroscopic guidance since an embolus can emerge from the loosened thrombus due to radiocontrast injection and catheter manipulation. The popliteal vein of the affected extremity is preferred for access in iliac and femoropopliteal venous thrombosis. This approach allows performing the intervention in the same direction as the venous valves open, therefore enabling easier access while avoiding any unintentional entry to the sub-branches (34). When both the femoral and the popliteal veins are obstructed, jugular or contralateral femoral vein can be used alternatively (35). With the purpose of preservation of venous valvular functions and maintenance of venous circulation, a tibial vein approach might be additionally required for removing the thrombus in popliteal vein. Routine use of venography is recommended after achieving venous access (36). The main venographic finding of DVT is the identification of an intraluminal filling defect. The other findings include an interruption of anatomical continuity of the vein, septation or a fold-like image of the venous wall (26).

A consensus has not been reached on the regarding the use of a particular thrombolytic agent, the method and the treatment dose in venous thrombosis. Streptokinase and urokinase are fibrin-non-specific thrombolytic agents. Streptokinase has a high risk of hemorrhagic complications and may lead to allergic reactions (28). Previously the most commonly used agent in the catheter-directed thrombolytic treatment of DVT was urokinase. However, tissue plasminogen activator (tPA), which is a fibrin-specific thrombolytic agent, has recently become the first choice (27). Novel thrombolytic agents, reteplase and tenecteplase activate thrombus-related plasminogen more specifically; however, experience on the use of these agents in CDT is limited. American Society of Interventional Radiology recommends 120.000180.000 unit/hour urokinase, $0.5-1.0 \mathrm{mg} /$ hour tPA, 0.25-0.75 unit/hour reteplase, or $0.25-0.5 \mathrm{mg} / \mathrm{hour}$ tenecteplase in catheter-directed thrombolytic treatment of unilateral lower extremity thrombosis (26). However, these doses should be adjusted according to the status of the patient, the severity of thrombosis and the potential risk of hemorrhage.

Patients undergoing thrombolytic treatment should be preferentially followed-up in intensive care units. Bedrest should be provided while paying utmost attention to immobilization of the catheterized extremity. The byproducts of thrombolytic agents are thrombogenic and can trigger thrombin production. Therefore, it is necessary to initiate anticoagulation simultaneously with thrombolytic treatment. Bodyweight-adjusted, low-dose unfractionated heparin protocol should be preferred to decrease the peri-procedural hemorrhage risk, and bolus heparin administration should be avoided (18). The dose should be adjusted by activated partial thromboplastin time (aPTT) assessment at every 4-6 hours, and the aPTT should be maintained at 1.5-2 folds of baseline aPTT level (34). Intermittent evaluation of hematocrit, thrombocyte count, and fibrinogen levels may be helpful in early recognition of hemorrhagic complications. Furthermore, clinical findings that address increased tendency to bleeding such as a peri-catheter leak and epistaxis should be monitored.

Control venography should be performed at 8-24 hour intervals for confirmation of the catheter position and for monitoring the success of thrombolysis (28). The optimal duration of thrombolytic treatment is controversial. Although some authors recommend continuation of treatment until the thrombus is fully resolved, other authors recommend cessation of thrombolytic treatment after 24-30 hours even if the thrombus has not been found to be completely resolved $(34,35)$. The reason for the limitation of treatment duration is the increased risk of hemorrhage with thrombolysis lasting more than 24 hours. The treatment can be completed within 24 hours in 95\% of patients, and clinical improvement can be observed within hours (34).

The most common complication of thrombolytic treatment is hemorrhage. In a meta-analysis involving 19 studies about CDT, the risk of major hemorrhage 
was reported as $8 \%$ (37). The risk of major hemorrhage necessitating blood transfusion is $0-25 \%$, and is related to various factors including the type and the dose of the thrombolytic agent, duration of the therapy and the simultaneous use of anticoagulants (27).

Another important complication of catheterdirected thrombolytic treatment is symptomatic PE which is encountered in $1-1.3 \%$ of patients $(18,30)$. The thrombus fragments that are formed during both the catheter-directed and the systemic thrombolytic treatments can be resolved by circulating thrombolytic agents. Although such fragments may go through the pulmonary circulation, this situation usually remains asymptomatic (27). The risk of PE is not significantly increased in catheter-directed treatment when compared to treatment with anticoagulants (26) and routine prophylactic use of permanent or temporary inferior vena cava (IVC) filters has not been recommended (28). However, IVC filter may be helpful in patients with limited cardiac reserve whose resistance against embolic events is low or in the presence of a free vena cava thrombus $(27,37)$ and the clinical conditions usually necessitates the use of temporary filters.

Anticoagulant therapy at a therapeutic dose should be inititated following the thrombolytic procedure with standard heparin. There is not enough evidence about the use of low-molecular-weight heparin. Although anticoagulant therapy can be paused for a short period during the withdrawal of the vascular sheath, the therapy should be resumed immediately after achievement of hemostasis. The anticoagulation should be continued for 3-6 months following the procedure; however, there is no consensus about the duration of the therapy (28). The patient should be followed-up clinically, and Doppler ultrasound or venography should be performed one year after the treatment. The anticoagulant therapy can be terminated if there is no predisposition to thrombosis. Patients are usually advised to use $30-40 \mathrm{mmHg}$ graded compression socks with for reduction of PTS risk (27).

The data about the long-term results of catheterdirected treatments in acute DVT are limited. In a randomized study of Elsharawy and Elzayat (38), 35 patients with IFDVT were assigned either to be treated with CDT or anticoagulant therapy only and followed for six-months. The authors reported that venous patency was better in the thrombolysis group and venous reflux was more severe in the anticoagulationonly group. Catheter-directed venous thrombolysis study is a randomized, multi-center study which compared anticoagulation in conjunction with CDT therapy with the anticoagulation only therapy in patients with IFDVT. Iliofemoral venous patency and 24-month PTS incidence was monitored for sixmonths. Illiofemoral venous patency was achieved in $65.9 \%$ of the thrombolysis patients, and in $47.4 \%$ of the anticoagulated patients. The absolute risk reduction regarding PTS was $14.4 \%$ in the thrombolysis patients (39). Acute Venous Thrombosis: Thrombus Removal with Adjunctive CDT (ATTRACT) study is a recent trial which involves 692 patients with acute DVT episode. The patients were randomized into two groups as the group treated with conventional anticoagulation only and the group treated with anticoagulants and catheter-directed thrombus removal. Although the addition of pharmacomechanical-thrombolysis to standard anticoagulant therapy did not reduce the risk of PTS, the severity scores for post-thrombotic disease were lower in the thrombolytic treatment group (40).

\section{Percutaneous Mechanical Thrombectomy}

Percutaneous mechanical thrombectomy (PMT) is the mechanical removal procedure of the thrombus by using catheter-directed interventional techniques and devices. This approach enables avoiding the risks of surgery and removing the thrombus rapidly in a similar manner to venous thrombectomy. Mechanical thrombectomy has gained a widespread use due to introduction of modern devices and development of novel endovascular techniques (41). The method of mechanical thrombectomy involves softening, fragmenting, and aspirating the thrombus by using rotational movements, rheolytic effect, or the ultrasound waves (42). Mechanical thrombectomy can additionally be performed through aspiration of the thrombus manually by using wide vascular sheaths and catheters (43).

The devices based on rotational movement remove the thrombus by breaking the thrombus into microscopic particles with the help of high-speed rotating helix or spiral-shaped wires. Endothelial damage may occur when these devices get in contact with the vessel wall (42). Rotational devices mimicking Archimedes' screw in which the moving 
part is covered with a nitinol scaffold were designed to overcome this problem, (Figure 1). The mechanism of action for devices working through rheolytic effect is to drag and remove the thrombus into the device with the help of a "vortex" formed by spraying highspeed fluid onto the thrombus (Figure 2). These devices are suggested to cause less endothelial and valvular damage compared to rotational devices since there are no moving parts in direct contact with the vessel wall (30). However, it was asserted that release of adenosine and potassium as a consequence of hemolysis caused by administration of high-pressure fluids, may lead to bradycardia (43). Ultrasoundmediated devices cause expansion and loosening in the fibrin structure of thrombus through emission of radial, high frequency, low-energy waves. Thus, the permeability of the thrombus is increased, resulting in an increased exposure of plasminogen receptor sites to thrombolytic agent thus enhancing the impact of thrombolysis. Such devices were suggested to cause less endothelial damage when compared to rotational

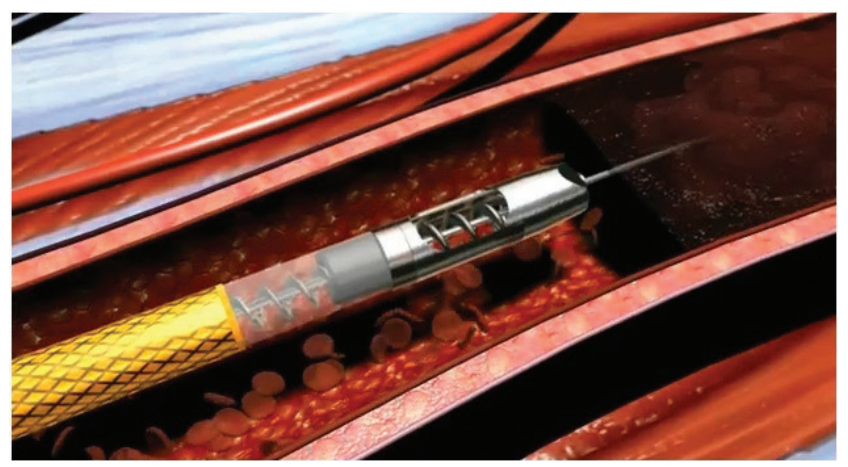

Figure 1. Rotational thrombectomy device

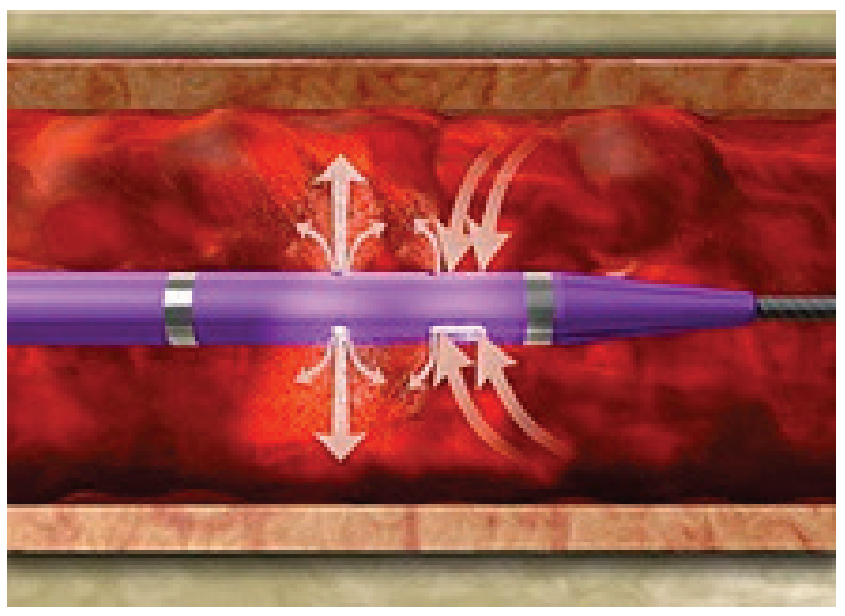

Figure 2. Rheolytic thrombectomy device devices and less hemolysis compared to rheolytic devices (42).

Although PMT can be used solely to remove the thrombus, it is commonly used in conjunction with catheter-directed thrombolytic treatment. Concomitant use of PMT and CDT methods increases the effectiveness of pharmacological thrombolysis, limits both the dose and duration of thrombolytic agent and prevents thrombolysis-related morbidities, particularly the hemorrhagic complications (44). This combined treatment approach is named as pharmacomechanical thrombolysis. Pharmacomechanical thrombolysis reduces thrombus burden especially in massive long-segment thrombi and facilitates the removal of residual or resistant thrombus in prolonged thrombolysis (>36 hours) (35). In cases that only one of the femoropopliteal or iliac segments is involved, mechanical thrombolysis can be effective. However, if thrombus has lead to obstruction of two or more segments, a combined treatment approach should be preferred (34). When mechanical thrombectomy is used alone the risk of clinical PE increases and the chance of effective decreases so using this method without employing thrombolysis is not recommended. Recently published guidelines also recommend using pharmacomechanical thrombectomy when appropriate equipment and sufficient experience are present (26). Pharmacomechanical thrombolysis yields significant reduction in thrombolytic agent dose, infusion period, number of interventions, and fluoroscopy time. However, using IVC filter as a preventive measure may be preferred before the procedure when pharmacological thrombolysis is contraindicated (28).

In a meta-analysis of sixteen retrospective studies involving 481 patients who had undergone mechanical thrombectomy, the ratio of patients with $50 \%$ or more vessel lumen patency following the treatment was found to be $83-100 \%$. The rates of symptomatic PE and hemorrhage necessitating blood transfusion were $1 \%$ and $7.5 \%$, respectively (42). Although these results indicate that PMT method is effective and reliable, randomized clinical studies showing short-term and long-term results are needed.

Percutaneous Venous Angioplasty and Stenting

In acute DVT, residual thrombus or venous outlet stenosis may remain despite early thrombus 
removal with interventional treatments or surgical thrombectomy. Management of such lesions may require percutaneous transluminal angioplasty (PTA) and stenting. The application of PTA or stent should be considered when the vessel diameter is reduced, flow is slow, and collateral veins are visualized during contrast injection (45).

Any residual lesion determined during the initial thrombolysis should not be left behind and treated by using endovascular methods to prevent early thrombus reformation or stenosis. An aggressive management in iliac venous stenosis helps to maintain venous patency in both the early and late periods $(46,47)$. The rate of achieving venous patency and eliminating clinical symptoms are reduced if the iliofemoral obstruction is not relieved immediately following thrombolysis (35). Combining PTA and stenting procedures with the thrombus removal techniques -as complementary measures- may reduce the risks of thrombus recurrence and PTS, increase the quality of life and facilitate healing of venous ulcers by eliminating the underlying venous obstruction (48).

Since the fibrotic nature of venous obstructions can result in elastic re-coil after the balloon angioplasty, stent placement is usually preferred in iliac vein obstructions (26). Residual iliac vein lesions can be either stenosis and residual thrombosis or a combination of both. Stenting is an effective treatment option in both scenarios since the stent restores the luminal patency and fixes the residual thrombus to the vessel wall.

Pathologies related with a permanent local narrowing of the vessel such as a thrombolysisresistant organized thrombus or an external compression of the vein by a tumor can also be treated by stenting (27). May-thurner syndrome, also known as the Cockett syndrome, is the development of a left-sided IFDVT due to the compression of the left common iliac vein by the right common iliac artery. In this syndrome, stenting the iliac vein after removing the iliac venous thrombus prevents recurrence of compression (18).

Self-expanding stents are usually preffered in endovascular interventions of the venous system. It is recommended to use $18-22 \mathrm{~mm}, 14-18 \mathrm{~mm}, 12-$ $14 \mathrm{~mm}$ and 10-12 mm sized stents for IVC, common iliac vein, external iliac vein, and common femoral vein, respectively. Balloon-expandable stents can be used for preventing the collapse of the stent or management of the stenosis when self-expandable stents have failed (35). If the adequate venous blood flow has not been achieved, the stent can be placed into the common femoral vein along the inguinal ligament to eliminate stenosis completely (49). In such cases, especially if the blood flow in the deep femoral vein is reduced, temporary arteriovenous fistula (AVF) can be constructed to increase femoral venous blood flow.

For the treatment of iliac stenosis after CDT, percutaneous catheter-directed thrombectomy or surgical venous thrombectomy, a stenting procedure is recommended; whereas in limited occlusive lesions of the femoral vein PTA without stenting is recommended by American Heart Association. Furthermore, it was emphasized that the general anticoagulant treatment protocol used in DVT patients should be used following the implantation of the venous stent and antiaggregant therapy should be added in patients with high risk of thrombus recurrence (33).

\section{Venous Thrombectomy}

Surgical thrombectomy is the removal of thrombus located in the deep veins via main femoral vein incision by using a thrombectomy catheter. This method was first described by Läwen in 1937 and became popular in the following years. However, the milestone in the history of venous thrombectomy was the demonstration of increased venous insufficiency and venous valvular dysfunction within five years after the operation in 1968 by Lansing and Davis. Although the study was deficient regarding methodological aspects, it was well recognized in the world, and the venous thrombectomy has then been performed in a few numbers of centers (50). However, the introduction of balloon catheters (Fogarty catheter), intraoperative venography and changes in postoperative anticoagulation protocols popularized venous thrombectomy again.

Performing venography to define the proximal and distal extensions of the thrombus before venous thrombectomy is important. The procedure should be done under fluoroscopic guidance particularly in cases with thrombus of vena cava. Methods that are used to prevent iatrogenic PE in cases with a free vena cava thrombus are using vena cava filters, temporary blockage by placing a balloon catheter to proximal of the thrombus, and positive pressure ventilation (51). It 
is recommended to perform intraoperative venography for assessment of blood flow in iliac veins and vena cava, and establishig an AVF between the saphenous vein and the femoral artery until endothelization is completed in the thrombogenic lumen (31). Continuation of postoperative oral anticoagulant therapy for at least one year is required (51).

In a study conducted by Scandinavian researchers, IFDVT patients on anticoagulant therapy were compared to IFDVT patients who had undergone venous thrombectomy with temporary AVF in addition to anticoagulant therapy. They reported that, in surgical patients, venous patency in iliofemoral veins was better and valvular functions of femoropopliteal veins were well-preserved in the early period (52). Ten-year follow-up of the same patient group revealed that iliac vein occlusion rate was $59 \%$ in anticoagulant therapy group while it was $17 \%$ in the surgical group. Furthermore, less edema and ulceration rates were observed in thrombectomy patients (53). In a meta-analysis comparing venous thrombectomy to anticoagulant therapy alone, thrombectomy was found to significantly reduce PTS and venous reflux; however, these studies were not able to reach to a satisfactory level of evidence (54).

Advanced age, malignancy, local wound healing problems, and comorbidities may increase the risk of surgery (55). Venous thrombectomy is usually preferred in patients in whom the pharmacological thrombolysis is contraindicated. When the other treatment methods have failed in phlegmasia cerulea dolens ( $P C D)$, venous thrombectomy is the treatment of choice for relieving the symptoms and correcting circulatory problems that threaten the vitality of extremity (56). Recent guidelines have recommended using CDT and percutaneous pharmacomechanical methods as the first-line treatment in acute DVT. Venous thrombectomy should be preserved for cases with a well functional capacity, and a life expectancy of more than one year. Thrombectomy should be performed by an experienced team of surgeons only when the methods mentioned above are contraindicated and the symptoms are present for less than seven days $(6,7)$.

\section{Conclusion}

The morbidity and mortality associated with DVT are potentially preventable. The mechanical and pharmacological treatment methods aiming to achieve venous patency in acute DVT are beneficial in both the early and late periods. The innovations in surgical and endovascular techniques have made it possible to resolve symptoms by removing the thrombosis, to treat extremity-threatening circulatory problems, and to avoid venous occlusion and valvular incompetence as well as to decrease morbidity of PTS. Early thrombus removal in patients with severe venous thrombosis is usually done by CDT methods. Pharmacomechanical thrombolysis methods have come forward in acute thrombus removal. It can be asserted that thrombus removal methods for treatment of acute DVT will be more popular in the future as clinical experience on interventional methods is increased, innovations related to endovascular methods are achieved, and fast-acting pharmacological thrombolytic agents with less hemorrhagic complications are produced. Randomized studies investigating the results of endovascular treatments in acute DVT are ongoing, and it is believed that the results of these studies will change the current guidelines radically. However, conventional anticoagulant therapy still constitutes the fundamental of acute DVT treatment, and it is recommended to use endovascular treatment methods in the experienced clinics and in selected patients.

Peer-review: Externally and internally peerreviewed.

\section{Authorship Contributions}

Concept: T.K., S.D., B.D., Design: T.K., S.D., B.D., Data Collection or Processing: T.K., B.D., Analysis or Interpretation: T.K., S.D., Literature Search: T.K., S.D., Writing: T.K., S.D., B.D.

Conflict of Interest: No conflict of interest was declared by the authors.

Financial Disclosure: The authors declared that this study received no financial support.

\section{References}

1. Silverstein MD, Heit JA, Mohr DN, Petterson TM, O'Fallon WM, Melton LJ. Trends in the incidence of deep vein thrombosis and pulmonary embolism: a 25-year population-based study. Arch Intern Med 1998; 158: 585-93.

2. Pollack CV Jr. Advanced management of acute illiofemoral deep venous thrombosis: emergency department and beyond. Ann Emerg Med 2011; 57: 590-9.

3. Kearon C. Natural history of venous thromboembolism. Circulation 2003; 107: 122-130. 
4. Galanaud JP, Kahn SR. Postthrombotic syndrome: a 2014 update. Curr Opin Cardiol 2014; 29: 514-9.

5. Kahn SR, Shbalko H, Lamping DL, Holcroft CA, Shrier I, Miron MJ, et al. Determinants of health-related quality of life during the 2 years following deep vein thrombosis. J Thromb Haemost 2008; 6: 1105-12.

6. Kearon C, Akl EA, Comerota AJ, Prandoni P, Bounameaux $\mathrm{H}$, Goldhaber SZ, et al. Antithrombotic therapy for VTE disease: Antithrombotic Therapy and Prevention of Thrombosis, 9th ed: American Collage of Chest Physicians Evidience-Based Clinical Practice Guidelines. Chest 2012; 141: e419S-94S.

7. Jaff MR, McMurty MS, Archer SL, Cushman M, Goldenberg N, Goldhaber SZ, et al. Management of massive and submassive pulmonary embolism, iliofemoral deep vein thrombosis, and chronic thromboembolic pulmonary hypertension: a scientific statement from the American Heart Association. Circulation 2011; 123: 1788-830.

8. Galli M, Ageno W, Squizzato A, Dentali F, Manfredi E, Steidl $L$, et al. Residual venous obstruction in patients with a single episode of deep vein thrombosis and in patients with recurrent deep vein thrombosis Thromb Haemost 2005; 94: 93-5.

9. Jezovnik $M K$, Poredos $P$. Factors influencing the recanalization rate of deep venous thrombosis. Int Angiol 2012; 31: 169-75.

10. Young L, Ockelford P, Milne D, Rolfe-Vyson V, Mckelvie S, Harper P. Post-treatment residual thrombus increases the risk of recurrent deep vein thrombosis and mortality. J Thromb Haemost 2006; 4: 1919-24.

11. Prandoni $P$, Lensing AW, Prins $M H$, Bernardi E, Marchiori A, Bagatella $P$, et al. Residual venous thrombosis as a predictive factor of recurrent venous thromboembolism. Ann Intern Med 2002; 137: 955-60.

12. Tick LW, Doggen CJ, Rosendaal FR, Faber WR, Bousema MT, Mackaay AJC, et al. Predictors of the post-thrombotic syndrome with non-invasive venous examinations in patients 6 weeks after a fiest episode of deep vein thrombosis. J Thromb Haemost 2010; 8: 2685-92.

13. Prandoni $P$, Frulla $M$, Sartor $D$, Concolato A, Girolami A. Vein abnormalities and the post-thrombotic syndrome. J Thromb Haemost 2005; 3: 401-2.

14. Baldwin MJ, Moore HM, Rudarakanchana N, Gohel M, Davies AH. Post-thrombotic syndrome: a clinical review. J Thromb Haemost 2013; 11: 795-805.

15. Brandjes DP, Büller HR, Heijboer H, Huisman MV, Rijk MD, Jagt $H$. Randomised trial of effect of compression stockings in patients with symptomatic proximal-vein thrombosis. Lancet 1997; 349: 759-62.

16. Prandoni $P$, Lensing AW, Prins $M H$, Frualla $M$, Marchiori $A$, Bernardi E, et al. Below-Knee Elastic Compression Stockings To Prevent the Post-Thrombotic Syndrome. Ann Intern Med 2004; 141: 249-56.

17. Raju $S$, Fountain T, Neglén $P$, Devidas $M$. Axial transformation of the profunda femoris vein. J Vasc Surg 1998; 27: 651-9.

18. Jenkins JS, Michael P. Deep venous thrombosis: An interventionalist's approach. Ochsner J 2014; 14: 633-40.
19. Stallworth JM, Bradham GB, Kletke RR, Price Jr PG. Phlegmasia cerulea dolens: a 10 year review. Ann Surg 1965; 161: 802-11.

20. Qvarfordt P, Eklöf B, Ohlin P. Intramuscular pressure in the lower leg in deep vein thrombosis and phlegmasia cerulea dolens. Ann Surg 1983; 197: 450-3.

21. Prandoni P, Villalta S, Bagatella P, Rossi L, Marchiori A, Piccioli A, et al. The clinical course of deep-vein thrombosis. Prospective longterm follow-up of 528 symptomatic patients. Haematologica 1997; 82: 423-8.

22. Douketis JD, Crowther MA, Foster GA, Gingsberg JS. Does the location of thrombosis determine the risk of disease reccurence in patients with proximal deep vein thrombosis. Am J Med 2001; 110: 515-9.

23. Akesson H, Brudin L, Dahlström JA, Eklöf B, Ohlin P, Plate G. Venous function assessed during a 5 year period after acute iliofemoral venous thrombosis treated with anticoagulation. Eur J Vasc Surg 1990; 4: 43-8.

24. Kahn SR, Shrier I, Julian JA, Ducruet T, Arsenault L, Miron MJ, et al. Determinants and time course of the postthrombotic syndrome after acute deep venous thrombosis. Ann Intern Med 2008; 149: 698-707.

25. Comerota AJ. Randomized trial evidence supporting a strategy of thrombus removal for acute DVT. Semin Vasc Surg 23: 192-8.

26. Vedantham S, Thorpe PE, Cardella JF, Grassi CJ, Patel NH, Ferral $\mathrm{H}$, et al. Quality improvement guidelines for the treatment of lower extremity deep vein thrombosis with use of endovascular thrombus removal. J Vasc Interv Radiol 2009; (7 Suppl): 227-39.

27. Shrafuddin MJ, Sun S, Hoballah JJ, Youness FM, Sharp WJ, Roh BS. Endovascular management of venous thrombotic and occlusive diseases of the lower extremities. J Vasc Interv Radiol 2003; 14: 405-23.

28. Meissner MH, Gloviczki P, Comerota AJ, Dalsing MC, Eklof BG, Gillsepie DL, et al. Early thrombus removal strategies for acute deep venous thrombosis: clinical practice guidelines of the Society for Vascular Surgery and the American Venous Forum. J Vasc Surg 2012; 55: 1449-62.

29. Comerota AJ, Gravett MH. Iliofemoral venous thrombosis. J Vasc Surg 2007; 46: 1065-76.

30. Augustinos $P$, Ouriel K. Invasive approaches to treatment of venous thromboembolism. Circulation 2004; 110: 127-34.

31. Dean A, Yap SL, Bhamidipaty V. Management of ilio-femoral deep vein thrombosis: a hybrid approach. J Vasc Med Surg 2014; 2: 131.

32. Castaneda F, Li R, Young K, Swischuk JL, Smouse B, Brady T. Catheter-directed thrombolysis in deep venous thrombosis with use of reteplase: immediate results and complications from a pilot study. J Vasc Interv Radiol 2002; 13: 577-80.

33. Mewissen MW, Seabrook GR, Meissner MH, Cynamon J, Labropoulos N, Haughton SH. Catheter-directed thrombolysis for lower extremity deep venous thrombosis: report of a national multicenter registry. Radiology 1999; 211: 39-49.

34. Sharifi M. Modern management of deep venous thrombosis. Vascular Disease Management 2014; 11: E2-E11. 
35. Kölbel T, Gottsäter A, Kühme T, Lindh M, Ivancev K. Endovascular treatment of venous occlusive disease. Ann Vasc Dis 2008; 1: 91101.

36. Kamida CB, Kistner RL, Eklof B, et al. Lower extremity ascending and descending phlebography. In: Gloviczki, P, Yao JST, editors. Handbook of Venous Disorders, 2nd ed: Guidelines of the American Venous Forum. Great Britain: Arnold; 2001. p.132-9.

37. Vedantham S. Interventional approaches to deep vein thrombosis. Am J Hematol 2012 87: 113-8.

38. Elsharawy M, Elzayat E. Early results of thrombolysis vs anticoagulation in iliofemoral venous thrombosis. A randomised clinical trial. Eur J Vasc Endovasc Surg 2002; 24: 209-14.

39. Enden T, Haig Y, Kløw NE, Slagsvold CE, Sandvik L, Ghanima W, et al. Long-term outcome after additional catheter-directed thrombolysis versus standard treatment for acute iliofemoral deep vein thrombosis (the CaVenT study): a randomised controlled trial. Lancet 2012; 379: 31-8.

40. Vedantham S, Goldhaber SZ, Julian JA, Kahn SR, Jaff MR, Cohen DJ, et al. Pharmacomechanical Catheter-Directed Thrombolysis for Deep-Vein Thrombosis. N Engl J Med 2017; 377: 2240-52.

41. Wildberger JE, Schmitz-Rode $T$, Schubert $H$, Günther RW. Percutaneousvenous thrombectomy with the use of a balloon sheath: first in vitroinvestigations of a new low-tech concept. Invest Radiol 2000; 35: 352-8.

42. Karthikesalingam A, Young EL, Hinchliffe RJ, Lotfus IM, Thampson $\mathrm{MM}$, Holt PJE. A systematic review of percutaneous mechanical thrombectomy in the treatment of deep venous thrombosis. Eur J Vasc Endovasc Surg 2011; 41: 554-65.

43. Oğuzkurt L, Ozkan U, Gülcan O, Koca N, Gür S. Endovascular treatment of acute and subacute iliofemoral deep venous thrombosis by using manual aspiration thrombectomy: longterm results of 139 patients in a single center. Diagn Interv Radiol 2012; 18: 410-6.

44. Arko FR, Davis CM, Murphy EH, Smith ST, Timaran $\mathrm{CH}$, Modrall JG, et al. Aggressive percutaneous mechanical thrombectomy deep venous thrombosis early clinical results. Arch Surg 2007; 142: 513-9.

45. Raju S, Owen S Jr, Neglen P. The clinical impact of iliac venous stents in the management of chronic venous insufficiency. J Vasc Surg 2002; 35: 8-15.
46. Kwak HS, Han YM, Lee YS, Jin GY, Chung GH. Stents in common illiac vein obstruction with acute ipsilateral deep venous thrombosis: early and late results. J Vasc Interv Radiol 2005; 16: 815-22.

47. Kölbel $T$, Lindh $M$, Holst J, Uher P, Eriksson KF, Sonesson B, et al. Extensive acute deep vein thrombosis of the iliocaval segment: midterm results of thrombolysis and stent placement. J Vasc Interv Radiol 2007; 18: 243-50.

48. Hartung $\mathrm{O}$, Loundou AD, Barthelemy P, Arnoux D, Boufi M, Alimi YS. Endovascular management of chronic disabling ilio-caval obstructive lesions: long-term results. Eur J Vasc Endovasc Surg 2009; 38: 118-24.

49. Negl'en P, Tackett TP Jr, Raju S. Venous stenting across the inguinal ligament. J Vasc Surg 2008; 48: 1255-61.

50. Eklöf B. Surgical thrombectomy for iliofemoral venous thrombosis revisited. J Vasc Surg 2011; 54: 897-900.

51. Comerota AJ. The current role of operative venous thrombectomy in deep vein thrombosis. Semin Vasc Surg 2012; 25: 2-12.

52. Plate $G$, Einarsson $E$, Ohlin $P$, Jensen $R$, Qvarfordt $P$, Eklöf $B$. Thrombectomy with temporary arteriovenous fistula: the treatment of choice in acute iliofemoral venous thrombosis. J Vasc Surg 1984; 1: 867-76.

53. Plate G, Eklof B, Norgren L, Ohlin P, Dahlström JA. Venous thrombectomy for iliofemoral vein thrombosis-10-year results of a prospective randomized study. Eur J Vasc Endovasc Surg 1997; 14: 367-74.

54. Casey ET, Murad MH, Zumaeta-Garcia M, Elamin MB, Shi Q, Erwin PJ, et al. Treatment of acute iliofemoral deep vein thrombosis. J Vasc Surg 2012; 55: 1463-73.

55. Katsukata N, Mashiko K, Matsumoto H. Surgical venous thrombectomy for Japanese patients with acute deep vein thrombosis: a review of 5 years' experience. J Nippon Med Sch 2010; 77: 155-9.

56. Chinsakchai K, Ten Duis K, Moll FL, Borst GJ. Trends in management of phlegmasia cerulea dolens. Vasc Endovascular Surg 2011; 45: 5-14. 